\title{
A Retrospective Analysis of Antipsychotic Medication Use with Concomitant Clinical Evaluation in Outpatient Psychiatry Department in Palestine
}

\author{
Manal Ihbeasheh ${ }^{1, *}$, Ikhlas Jarar², Waleed Sweileh ${ }^{3}$ \\ ${ }^{1}$ Department of Biochemistry \& Molecular Biology, Faculty of Medicine and Health Sciences, An-Najah National University, Nablus, \\ Palestine \\ ${ }^{2}$ Ministry of Health Jenin Palestine \\ ${ }^{3}$ Department of Pharmacology, Faculty of Medicine and Health Sciences, An-Najah National University, Nablus, Palestine \\ *Corresponding Author: mailto:manalih82@yahoo.com
}

Copyright $@ 2014$ Horizon Research Publishing All rights reserved.

\begin{abstract}
Objectives: The objective of this paper was to study antipsychotic medication use in the outpatient psychiatry department in Palestine. Methodology: This is a cross sectional study carried out in Palestine on schizophrenic patients aged between $20-65$ whose medications have not been changed in the past six months and they did not have an acute attack in the last year. Information regarding antipsychotic medications use was obtained from patients' medical files; patients' psychiatric symptoms were evaluated using the Expanded Brief Psychiatric Rating Scale (BPRS-E).Results: More than half (53.1\%) of 150 patients were on antipsychotic polypharmacy (APP) with average daily dose of $546.9 \pm 254.9 \mathrm{mg}$ chlorpromazine equivalents. The average number (mean \pm SD) of medications a patient received was $1.7 \pm 0.7$. One third of patients on APP regimen received atypical antipsychotic and all of them received at least one conventional antipsychotic. Factors significantly and positively associated with APP were: use of anticholinergic agents $(P<0.001)$, conventional antipsychotics $(P<0.001)$, depot formulations $(P<0.001)$ and prescribing higher doses of antipsychotics $(P<0.001)$. Discussion and Conclusion: Antipsychotic polypharmacy in this study was common. Adherence to international guidelines in the treatment of schizophrenia is recommended.
\end{abstract}

Keywords Monotherapy, Polypharmacy, Antipsychotic Medications Use

\section{Introduction}

Schizophrenia is a chronic mental illness that requires long-term treatment with antipsychotic medications (Weiss et al., 2011). Antipsychotic monotherapy (APM) is recognized as the treatment of choice (Faries et al., 2005). Simultaneous treatment with multiple antipsychotics (APP) is advocated only as timely limited last-line strategy for patients who have experienced suboptimal responses to antipsychotic monotherapy (APM) or when switching from one antipsychotic to another (overlap and taper) and for not longer than 60 days (Lehman et al., 2004, Stahl and Grady, 2004, Langan and Shajahan, 2010). Patients on APP have higher rates of metabolic syndrome and lipid markers of insulin resistance (Christoph et al., 2006) .Furthermore, APP is associated with greater risk of drug-drug interactions, poor medication adherence (Freudenreich and Goff, 2002, Stahl and Grady, 2004, Carnahan et al., 2006, Weinmann et al., 2009), high-dose prescribing ,adverse effect burden (Barnes and Paton, 2011), higher healthcare costs (Alessi-Severini et al., 2008) and increased anticholinergic drug prescriptions (Kreyenbuhl et al., 2007).

Despite consistent recommendations of APM, antipsychotic polypharmacy is widespread in the treatment of schizophrenia (Covell et al., 2002, Miller and Craig, 2002, Weissman, 2002, Loosbrock et al., 2003, Schumacher et al., 2003, Tapp et al., 2003, Ganguly et al., 2004, Mojtabai and Olfson, 2010). Available antipsychotics include both conventional (typical) and new (atypical) antipsychotic medications. It is believed that conventional antipsychotics are less effective and have more serious extra-pyramidal adverse effects compared to atypical antipsychotics (Lieberman, 1996, Hong and Bishop, 2010). Despite this, atypical antipsychotics are not widely prescribed in many countries (Sartorius et al., 2002).

The objective of this study was to assess antipsychotic medications use in schizophrenic out-patients in a governmental psychiatric clinic in Palestine, with concomitant evaluation of their schizophrenic symptoms to highlight treatment practices in our country and see whether these practices abide by published guidelines or not . 


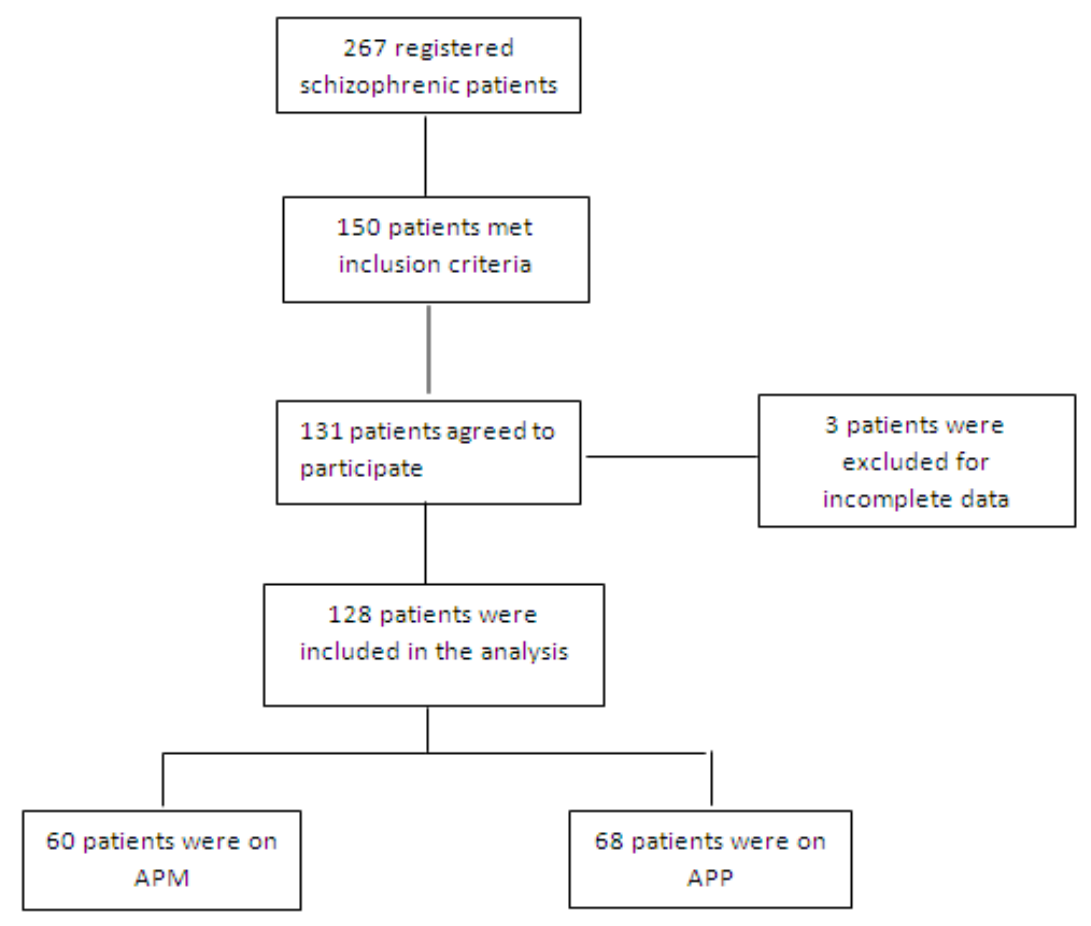

Abbreviations: APP =antipsychotic polypharmacy, APM=antipsychotic monotherapy

Chart 1. Patient sampling

\section{Methodology}

\subsection{Study Design and Patient Selection}

A cross sectional study was conducted between July 2012 and September 2012 at Al-Makhfiya psychiatric Health Center in Nablus, Palestine. Approval to perform the study was obtained from the Palestinian Ministry of Health and Institutional Review Board at An-Najah National University. Patients who were invited to participate fulfilled the following inclusion criteria: 1) their age was between 20 and $65,2)$ they were diagnosed with schizophrenia as defined by DSM-IV , 3) they had not been suffering from an acute attack of illness during the past year, and 4) their drug regimen had not been changed in the last 6 months. A convenient sample of 150 patients met the inclusion criteria during the study period. (Details of patients sampling are shown in Chart 1 below).

\subsection{Assessment and Measures}

The instrument used in this study consisted of three parts: part one collected socio-demographic and medication data from patients' medical files; part two was the psychiatric assessment and the last part was the calculation of chlorpromazine equivalent doses for the prescribed antipsychotics (APs).

Positive, negative, depression and manic schizophrenic symptoms were evaluated by a psychiatrist and well trained psychologists using the expanded Brief Psychiatric Rating Scale (BPRS-E) (Overall and Gorham, 1962, Lukoff et al.,
1986, Overall, 1988, Ventura et al., 1993) in the same visit. The BPRS-E consists of 24 items measuring psychiatric symptoms. Each item in BPRS-E is rated from $0-7$ based on the severity of the symptom where the highest score indicates the highest severity. BPRS-E measures four different dimensions: manic excitement/ disorganization, positive symptoms, negative symptoms and depression/ anxiety (Ruggeri et al., 2005). Positive symptom score (PSS) was based on the sum of score of the following: grandiosity, suspiciousness, hallucinations, unusual thought content and conceptual disorganization while negative symptom score (NSS) was based on the sum of score of the following symptoms: disorientation, blunted affect, emotional withdrawal, motor retardation, and mannerism and posturing. Manic excitement/ disorganization score was based on the sum of score of the following: elated mood, bizarre behavior, self neglect, excitement, distractibility, motor hyperactivity and mannerism and posturing. Depression/ anxiety score was based on the sum of score of the following: anxiety, depression, suicidality and tension.

Type and dose of AP medications prescribed by the psychiatrists were collected from the patients' medical records. Daily doses of APs, including depot APs, were converted to approximate chlorpromazine equivalents (CPZeq) using published guidelines (Shen, 2002, Woods, 2003). The CPZeq is a measure of the relative antipsychotic potencies of neuroleptics. They are generally expressed as a ratio, relative to the arbitrary value of 1 , which corresponds to the AP effects of chlorpromazine. For example, an AP drug with a CPZeq value of 100 would be 100 times more potent than chlorpromazine. 
Table 1. Baseline demographic and clinical data.

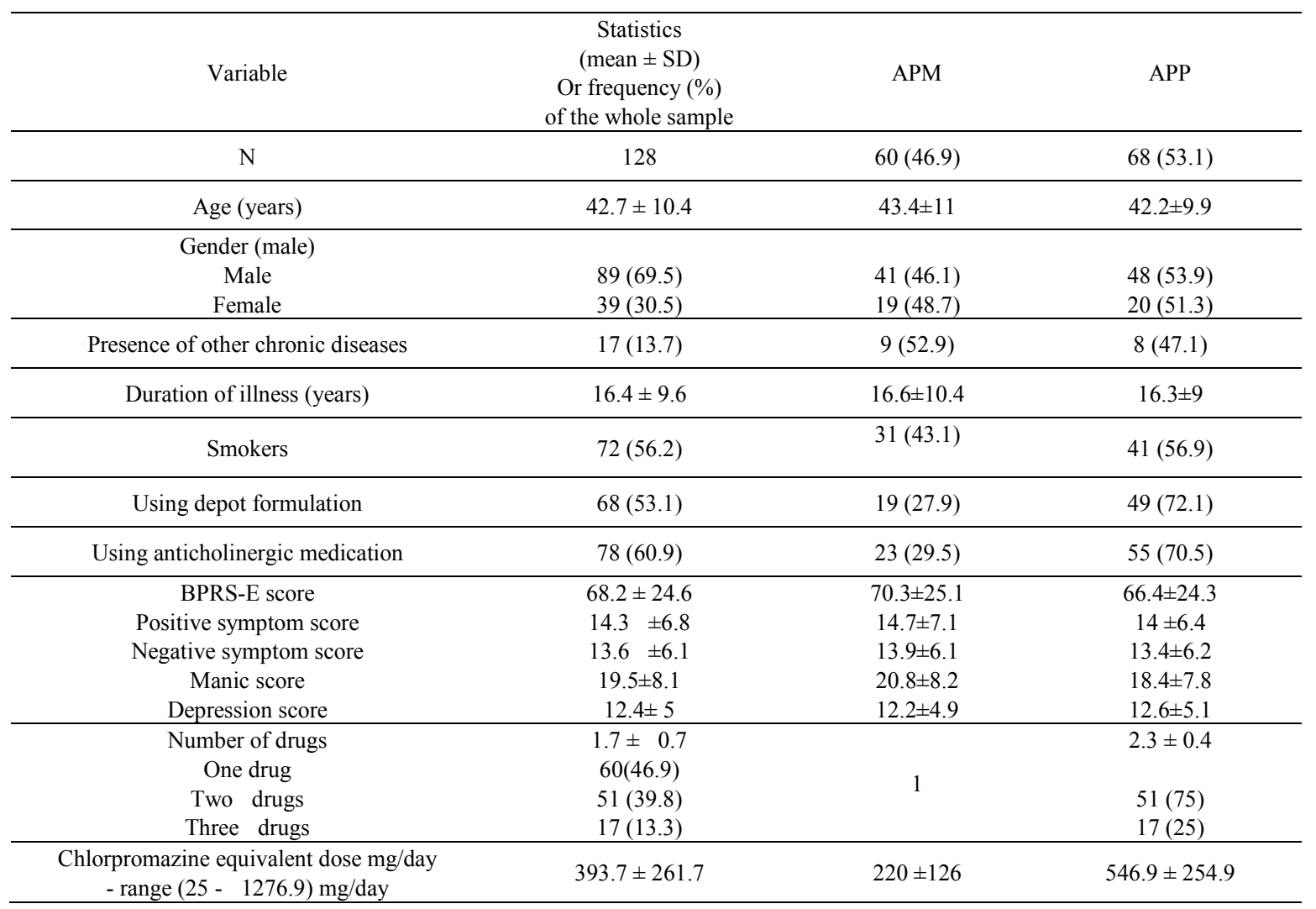

Abbreviations: APP =antipsychotic polypharmacy, APM = antipsychotic monotherapy, SD =standard deviation , BPRS-E =expanded Brief Psychiatric Rating Scale

\subsection{Data Analysis}

Continuous variables like age, duration of illness, CPZeq doses of AP , BPRS and its four dimensions scores were expressed as mean $\pm \mathrm{SD}$. Association between continuous variables and prescription pattern defined as APM and APP was carried out using independent sample $t$ test. Chi square test was applied to test differences between APP and APM with respect to categorical variables. All statistical analyses were conducted using Statistical Package for Social Sciences (SPSS; version 16.0).The conventional 5 percent significance level was used throughout the study.

\section{Results}

\subsection{Demographic and Clinical Characteristics of Patients}

One hundred and fifty, out of 267, schizophrenic patients met the inclusion criteria. One hundred and thirty one patients agreed to participate giving a response rate of $87.3 \%$. Three patients were excluded from analysis because of incomplete data. Of the 128 patients included in the analysis, $39(30.5 \%)$ were female and $89(69.5 \%)$ were male. Data related to sample number is shown in Chart 1 . The mean age of the patients was $42.7 \pm 10.4$ years (range $=20-65$ ). The mean duration of illness was $16.4 \pm 9.6$ years. Seventeen patients $(13.3 \%)$ had other non-psychiatric diseases. For the whole sample, the mean BPRS score of the patients was 68.2 \pm 24.6 with $14.3 \pm 6.8,13.6 \pm 6.1,19.5 \pm 8.1$ and $12.4 \pm 5$ for positive, negative, manic and depression symptoms scores respectively. Details regarding demographic and clinical characteristics of the studied patients are shown in Table 1.

\subsection{Patterns of Antipsychotic Use}

Sixty eight (53.1\%) patients were receiving APP. The AP medications most commonly prescribed in cases of polypharmacy were chlorpromazine $(53,77.9 \%)$, fluphenazine decaneoate depot formulation $(30,44.1 \%)$ and haloperidol $(28,41.2 \%)$. The mean numbers of APs for the whole sample and APP group were $1.7 \pm 0.7$ and $2.3 \pm 0.4$ respectively. About one third of patients on APP regimen received atypical AP and all of them received at least one conventional AP. More than half of patients (54.4\%) on APP received a conventional depot AP together with an oral conventional AP. For the whole sample, 68(53.1\%) of patients received depot formulation; $19(27.9 \%)$ of them were on APM regimen and 49(72.1\%) were on APP regimen. Details about therapeutic regimens for patients on polypharmacy and monptherapy are shown in Chart 2 and Chart 3 respectively. 


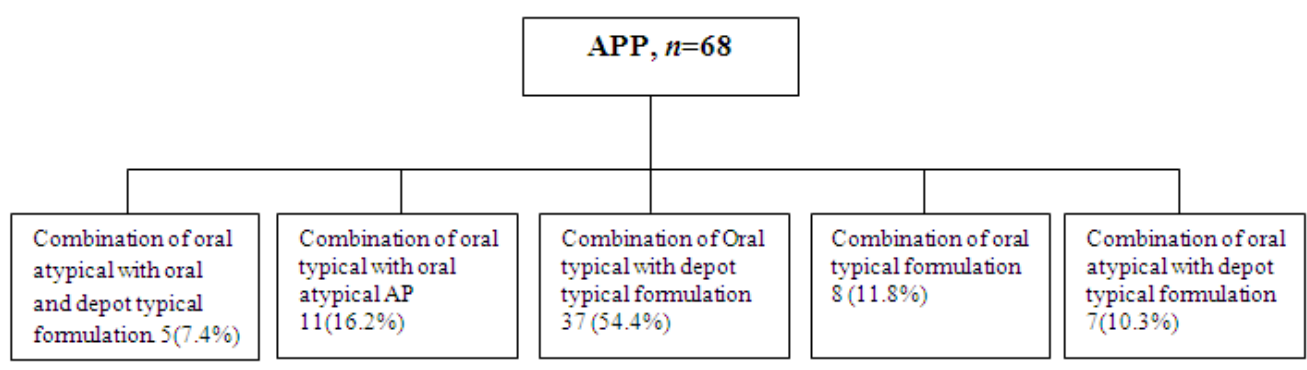

Abbreviations: APP =antipsychotic polypharmacy.

Chart 2. Therapeutic regimens for patients on antipsychotic polypharmacy (APP)

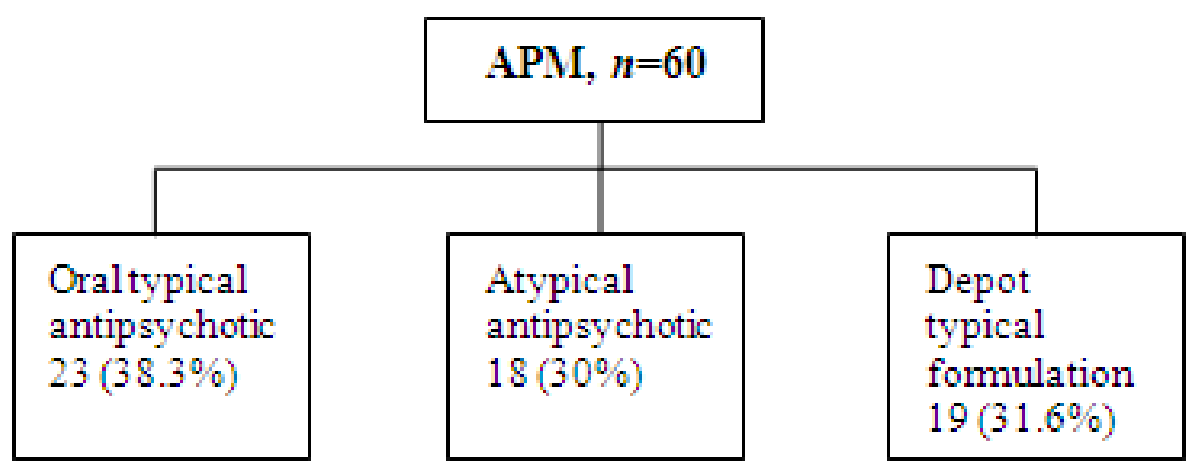

Abbreviations: APM=antipsychotic monotherapy

Chart 3. Therapeutic regimens for patients on antipsychotic monotherapy (APM)

Table 2. Association of antipsychotic prescription pattern with sociodemographic and clinical variables and medications type

\begin{tabular}{|c|c|c|c|}
\hline Demographic variable & APM & APP & $P$ value \\
\hline Age & $43.4 \pm 11$ & $42.2 \pm 9.9$ & 0.52 \\
\hline $\begin{array}{c}\text { Gender } \\
\text { Male } \\
\text { Female }\end{array}$ & $\begin{array}{l}41(46.1) \\
19(48.7) \\
\end{array}$ & $\begin{array}{l}48(53.9) \\
20(51.3)\end{array}$ & 0.78 \\
\hline Duration of illness (years) & $16.6 \pm 10.4$ & $16.3 \pm 9$ & 0.87 \\
\hline Smokers & $31(43.1)$ & $41(56.9)$ & 0.33 \\
\hline Presence of other chronic disease & $9(52.9)$ & $8(47.1)$ & 0.6 \\
\hline $\begin{array}{c}\text { BPRS-E score } \\
\text { Positive symptom score } \\
\text { Negative symptom score } \\
\text { Manic score } \\
\text { Depression score }\end{array}$ & $\begin{array}{l}70.3 \pm 25.1 \\
14.7 \pm 7.1 \\
13.9 \pm 6.1 \\
20.8 \pm 8.2 \\
12.2 \pm 4.9\end{array}$ & $\begin{array}{c}66.4 \pm 24.3 \\
14 \pm 6.4 \\
13.4 \pm 6.2 \\
18.4 \pm 7.8 \\
12.6 \pm 5.1\end{array}$ & $\begin{array}{c}0.38 \\
0.54 \\
0.67 \\
0.1 \\
0.69\end{array}$ \\
\hline Using typical depot formulations & $19(27.9)$ & $49(72.1)$ & $<0.001^{*}$ \\
\hline Using anti cholinergic medication & $23(29.5)$ & $55(70.5)$ & $<0.001^{*}$ \\
\hline Using conventional antipsychotics & $42(70 \%)$ & $68(100 \%)$ & $<0.001 *$ \\
\hline Using atypical antipsychotics & $18(30 \%)$ & $23(33.8 \%)$ & 0.64 \\
\hline Chlorpromazine equivalent dose $\mathrm{mg}$ /day & $220 \pm 126$ & $546.9 \pm 254.9$ & $<0.001^{*}$ \\
\hline Number of medications & 1 & $2.3 \pm 0.4$ & $<0.001 *$ \\
\hline
\end{tabular}

Abbreviations: APP = antipsychotic polypharmacy, APM = antipsychotic monotherapy, BPRS-E =expanded Brief Psychiatric Rating Scale, * significance $p$ value 
The average chlorpromazine equivalent daily dose (CPZeq) in $\mathrm{mg}$ for the total sample was $393.7 \pm 261.7$. The average CPZeq daily dose received in patients belong to APM and APP was $220 \pm 126$ and $546 \pm 254.9 \mathrm{mgs}$ respectively. Based on CPZeq dose, four (3.1\%) patients were receiving supramaximal dose of AP, defined as a daily dose exceeding $1000 \mathrm{mg} \mathrm{CPZ}$, and all of them were on APP regimen.

\subsection{Prescription Pattern Correlations}

Table 2 compares the characteristics of patients on monotherapy versus those on polypharmacy. There was no significant association between any socio-demographic variables and prescription pattern (monotherapy vs. polypharmacy). There was no significant difference in means of BPRS and its four dimensions between patients on APM and APP regimens. Factors that were significantly and positively associated with APP were using anticholinergic agents $(P<0.001)$, depot psychotropic formulations $(P<0.001)$, conventional antipsychotics $(P<0.001)$ as well as prescribing higher doses of APs $(P<0.001)$.

\section{Discussions}

The results of this study showed that more than half (53.1\%) of patients were on polypharmacy for long time which is at odds with clinical guidelines (Lehman et al., 2004, Stahl and Grady, 2004, Langan and Shajahan, 2010). The average number of AP was 1.7 while that reported previously in Palestine was 1.53 and that reported in Jordan, a neighboring country, was 2.47 medications per patient (Sweileh et al., 2004, Alshara et al., 2010).

Antipsychotic polypharmacy rates vary across studies. In the US, APP rates used to vary between $13 \%$ in outpatient clinics and 50\% in inpatients (Freudenreich et al., 2007). A study in USA indicated that about a third $(35.7 \%)$ of the patients were treated predominately with monotherapy ( $>300$ days); $26.9 \%$ were treated predominately with polypharmacy (>300 days) and $30.2 \%$ had a mix of both substantial monotherapy and polypharmacy treatment periods (61- 300 days of each) (Faries et al., 2005). The frequency of APP in two Chinese populations was $17.6 \%$ while in Japan and other East-Asian countries it was 90\% and 45\% respectively (Sim et al., 2004, Xiang et al., 2007). In the United Kingdom, $17.4 \%$ of the AP prescriptions were in the context of polypharmacy (Ranceva et al., 2010). In Jordan the rate of polypharmacy was $97.8 \%$. These discrepancies in APP prevalence across studies may be accounted for by differences in the definition of polypharmacy. Although most studies defined polypharmacy as any time with more than one AP (Xiang et al., 2007, Satake et al., 2011), others have set specific time requirements such as setting at least 14 days of concurrent AP use (Ganguly et al., 2004). Moreover, differences in study methods can generate different results too (Faries et al.,
2005, Xiang et al., 2007, Karaoğlan Kahiloğullari et al., 2008).

Based on the current findings of our study, there was no significant association between any socio-demographic variables and prescription pattern (monotherapy vs. polypharmacy). Moreover, we found that APP regimen was not associated with better patients' clinical outcome compared to APM regimens although patients on APP received significantly higher CPZeq daily doses of APs and larger number of adjuvant anticholinergic psychotropic medications and they over utilized both oral conventional AP agents in general and conventional APs in its depot formulation. A number of randomized clinical trials comparing patients on APM using clozapine with patients on APP using clozapine and respiridone concerning clinical outcomes were done and their results varied. For example, Josiassen (2005) found that APP using the latter combination was more effective at symptoms reduction than APM using clozapine (Josiassen et al., 2005). Freudenreich (2007), Honer (2006) and kotler (2004) found that there was no difference between APP (clozapine + respiridoone) and APM (clozpaine) in symptoms improvement on Positive and Negative Symptom Scale (PANSS) (Kotler et al., 2004, Honer et al., 2006, Freudenreich et al., 2007). Furthermore, Honer et al., (2006) observed that APP led to greater worsening of verbal working memory compared to APM (Honer et al., 2006).On the other hand, an observational study of amisulpride added to clozapine for psychosis unresponsive cases to clozapine monotherapy observed that clozapine combination led to greater improvement in symptoms on BPRS (Agelink et al., 2004).

Concerning daily AP dosages and prescription pattern, Kreyenbuhl et al, (2007) observed that dosages prescribed for patients receiving polypharmacy were the same or modestly higher than those prescribed for patients receiving monotherapy (Kreyenbuhl et al., 2007). Another study observed that CPZeq dose of patients on APP was significantly higher than those on APM and that was in accordance with our findings (Hayhurst et al., 2010). Also Barnes TR (2011) found that polypharmacy is a major contributor to high dose prescribing (Barnes and Paton, 2011). Our finding regarding the association between anti cholinergic agents use and APP appear consistent with previous studies and it may be partly accounted for by the expected higher occurrence of EPS in the APP group and partly by the attempt to prevent the anticipated EPS in patients receiving APP (Xiang et al., 2007, Hong and Bishop, 2010, Xiang et al., 2011). However, there are risks beyond the continuous use of anti cholinergic agents such as memory impairment, delirium and the reverse of the effect of atypical antipsychotics on cognitive deficit (Xiang et al., 2007). Our finding concerning the association of APP with over utilization of depot conventional AP was also proved by other studies. Researchers found that APP was associated with more use of depot APs, anticholinergic drugs and doses of APs compared with patients on APM (Xiang et al., 2007, Xiang et al., 2008). 
In conclusion, prescribing pattern in this study was not in accordance with guidelines. Antipsychotic polypharmacy was common and for long time with no better clinical outcomes based on BPRS-E. Educational interventions are important for physicians working in psychiatry regarding current guidelines for schizophrenia treatment.

\section{REFERENCES}

[1] Agelink, M., Kavuk, I., Ak, I., 2004. Clozapine with amisulpride for refractory schizophrenia. The American Journal of Psychiatry 161, 924-925.

[2] Alessi-Severini, S., Biscontri, R., Collins, D., Kozyrskyj, A., Sareen, J., Enns, M., 2008. Utilization and costs of antipsychotic agents: a Canadian population-based study,1996-2006 Psychiatric Services 59, 547-553.

[3] Alshara, M., Al-Shareef, Z., Mahasneh, B., 2010. Patterns of Drug Prescription for Jordanian Psychiatric Patients with Special Concern on Schizophrenia. The New Iraqi Journal of Medicine 6, 5-9.

[4] Barnes, T., Paton, C., 2011. Antipsychotic polypharmacy in schizophrenia: benefits and risks. CNS Drugs 25, 383-399.

[5] Carnahan, R., Lund, B., Perry, P., Chrischilles, E., 2006. Increased risk of extrapyramidal side-effect treatment associated with atypical antipsychotic polytherapy. Acta Psychiatrica Scandinavica 113, 135-141.

[6] Christoph, U., Correll, Anne, M., Frederickson, John, M., Kane, Peter Manu, 2006. Does antipsychotic polypharmacy increase the risk

[7] for metabolic syndrome? Psychiatric Services.

[8] Covell, N., Jackson, C., Evans, A., Essock, S., 2002. Antipsychotic prescribing practices in Connecticut's public mental health system: rates of changing medications and prescribing styles. Schizophrenia Bulletin 28, 17-29.

[9] Faries, D., Ascher-Svanum, H., Zhu, B., Correll, C., Kane, J., 2005. Antipsychotic monotherapy and polypharmacy in the naturalistic treatment of schizophrenia with atypical antipsychotics. BMC Psychiatry 5, 26.

[10] Freudenreich, O., Goff, D., 2002. Antipsychotic combination therapy in schizophrenia. A review of efficacy and risks of current combinations. Acta Psychiatrica Scandinavica 106, 323-330.

[11] Freudenreich, O., Henderson, D., Walsh, J., Culhane, M., Goff, D., 2007. Risperidone augmentation for schizophrenia partially responsive to clozapine: a double-blind, placebo-controlled trial. Schizophrenia Research 92, 90-94.

[12] Ganguly, R., Kotzan, J., Miller, L., Kennedy, K., Martin, B., 2004. Prevalence, trends, and factors associated with antipsychotic polypharmacy among Medicaid-eligible schizophrenia patients, 1998-2000. The Journal of Clinical Psychiatry 65, 1377-1388.

[13] Hayhurst, K., Drake, R., Lewis, S., 2010. Patient factors associated with receipt of combination antipsychotic drug therapy in the treatment of schizophrenia. Journal of
Psychopharmacology 24, 83-89

[14] Honer, W. G., Thornton, A. E., Chen, E. Y., Chan, R. C., Wong, J. O., Bergmann, A., Falkai, P., Pomarol-Clotet, E., McKenna, P. J., Stip, E., Williams, R., MacEwan, G. W., Wasan, K., Procyshyn, R., 2006. Clozapine alone versus clozapine and risperidone with refractory schizophrenia. The New England Journal of Medicine 354, 472-82.

[15] Hong, I., Bishop, J., 2010. Anticholinergic use in children and adolescents after initiation of antipsychotic therapy. The Annals of Pharmacotherapy 44, 1171-1180

[16] Josiassen, R., Joseph, A., Kohegyi, E., Stokes, S., Dadvand, M., Paing, W., Shaughnessy, R., 2005. Clozapine augmented with risperidone in the treatment of schizophrenia: a randomized, double-blind, placebo-controlled trial. The American Journal of Psychiatry 162, 130-136.

[17] Karaoğlan Kahiloğullari, A., Örsel, S., Emre Sargin, A., Hatiloğlu, U., Sezai Berber, M., Haluk Özbay, M., 2008. Changes in Drug Prescription Patterns in Schizophrenia in Five Years. Klinik Psikofarmakoloji Bulteni 18, 162-166.

[18] Kotler, M., Strous, R., Reznik, I., Shwartz, S., Weizman, A., Spivak, B., 2004. Sulpiride augmentation of olanzapine in the management of treatment-resistant chronic schizophrenia: evidence for improvement of mood symptomatology. International Clinical Psychopharmacology 19, 23-26.

[19] Kreyenbuhl, J., Valenstein, M., McCarthy, J., Ganoczy, D., Blow, F., 2007. Long-term antipsychotic polypharmacy in the VA health system: patient characteristics and treatment patterns. Psychiatric Services 58, 489-495.

[20] Langan, J., Shajahan, P., 2010. Antipsychotic polypharmacy: review of mechanisms, mortality and management. The Psychiatrist 34, 58-62.

[21] Lehman, A., Lieberman, J., Dixon, L., McGlashan, T., Miller, A., Perkins, D., Kreyenbuhl, J., 2004. Practice guideline for the treatment of patients with schizophrenia, second edition. The American Journal of Psychiatry 161, 1-56.

[22] Lieberman, J., 1996. Atypical antipsychotic drugs as a first-line treatment of schizophrenia: a rationale and hypothesis. The Journal of Clinical Psychiatry 57, 68-71.

[23] Loosbrock, D., Zhao, Z., Johnstone, B., Morris, L., 2003. Antipsychotic medication use patterns and associated costs of care for individuals with schizophrenia. The Journal of Mental Health Policy and Economics 6, 67-75.

[24] Lukoff, D., Liberman, R., Nuechterlein, K., 1986. Symptom monitoring in the rehabilitation of schizophrenic patients. Schizophrenia Bulletin 12, 578-602.

[25] Miller, A., Craig, C., 2002. Combination antipsychotics: pros, cons, and questions. Schizophrenia Bulletin 28, 105-109.

[26] Mojtabai, R., Olfson, M., 2010. National trends in psychotropic medication polypharmacy in office-based psychiatry. Archives of General Psychiatry 67, 26-36.

[27] Overall, J., 1988. The Brief Psychiatric Rating Scale (BPR S): recent developments in ascertainment and scaling. Psychopharmacology Bulletin 24, 97-98.

[28] Overall, J., Gorham, D., 1962. The Brief Psychiatric Rating Scale. Psychological Reports 10, 799-812. 
[29] Ranceva, N., Ashraf, W., Odelola, D., 2010. Antipsychotic polypharmacy in outpatients at Birch Hill Hospital: incidence and adherence to guidelines. Journal of Clinical Pharmacology 50, 699-704

[30] Ruggeri, M., Koeter, M., Schene, A., Bonetto, C., Vàzquez-Barquero, J., Becker, T., Knapp, M., Knudsen, H., Tansella, M., Thornicroft, G., Group., E. S., 2005. Factor solution of the BPRS-expanded version in schizophrenic outpatients living in five European countries. Schizophrenia Research 75, 107-117.

[31] Sartorius, N., Fleischhacker, W., Gjerris, A., Kern, U., Knapp, M., Leonard, B. E., Lieberman, J. A., López-Ibor, J. J., Van Raay, B., Twomey, E., 2002. The usefulness and use of second-generation antipsychotic medications. Current Opinion in Psychiatry 15, 1-51.

[32] Satake, N., Hazama, K., Sono, T., Takahashi, M., Ito, J., 2011. Changes in antipsychotic medication in clients of assertive community treatment in Japan: a one-year follow up. Clinical Practice and Epidemiology in Mental Health 19, 1-3.

[33] Schumacher, J., Makela, E., Griffin, H., 2003. Multiple antipsychotic medication prescribing patterns. The Annals of Pharmacotherapy 37, 951-955.

[34] Shen, Y., 2002. . Psychiatry .Beijing: People's medical publishing house

[35] Sim, K., Su, A., Fujii, S., Yang, S., Chong, M., Ungvari, G., Si, T., Chung, E., Tsang, H., Chan, Y., Heckers, S., Shinfuku, N., Tan, C., 2004. Antipsychotic polypharmacy in patients with schizophrenia: a multicentre comparative study in East Asia. British Journal of Clinical Pharmacology 58, 178-183.

[36] Stahl, S., Grady, M., 2004. A critical review of atypical antipsychotic utilization: comparing monotherapy with polypharmacy and augmentation. Current Medical Chemistry $11,313-327$.

[37] Sweileh, W., Jaradat, N., Al-Khayyat, A., 2004 Typical and Atypical Antipsychotic Drug Utilization in a Psychiatric
Clinic in Palestine. An-Najah University Journal 18, 39-47.

[38] Tapp, A., Wood, A., Secrest, L., Erdmann, J., Cubberley, L., Kilzieh, N., 2003. Combination antipsychotic therapy in clinical practice. Psychiatric Services 54, 55-59.

[39] Ventura, J., Green, M., Shaner, A., Liberman, R. P., 1993. Training and quality assurance on the BPRS: 'The Drift Busters'. International Journal of Methods in Psychiatric Research 3, 221-244.

[40] Weinmann, S., Read, J., Aderhold, V., 2009. Influence of antipsychotics on mortality in schizophrenia: systematic review. Schizophrenia Research 113, 1-11.

[41] Weiss, A., Movahed, R., Dym, H., 2011. Schizophrenia: current therapy and review. Journal of Oral and Maxillofacial Surgery 69, 192-198

[42] Weissman, E., 2002. Antipsychotic prescribing practices in the Veterans Healthcare Administration--New York metropolitan region. Schizophrenia Bulletin 28, 31-42.

[43] Woods, S., 2003. Chlorpromazine equivalent doses for the newer atypical antipsychotics. The Journal of Clinical Psychiatry 64, 663-667.

[44] Xiang, Y., Wang, C., Si, T., Lee, E., He, Y., Ungvari, G., Chiu, H., Yang, S., Chong, M., Tan, C., Kua, E., Fujii, S., Sim, K., Yong, K., Trivedi, J., Chung, E., Udomratn, P., Chee, K., Sartorius, N., Shinfuku, N., 2011. Use of anticholinergic drugs in patients with schizophrenia in Asia from 2001 to 2009. Pharmacopsychiatry 44, 114-118.

[45] Xiang, Y., Weng, Y., Leung, C., Tang, W., Ungvari, G., 2007. Clinical and social determinants of antipsychotic polypharmacy for Chinese patients with schizophrenia. Pharmacopsychiatry 40, 47-52.

[46] Xiang, Y., Weng, Y., Leung, C., Tang, W., Ungvari, G., 2008. Clinical and social correlates with the use of depot antipsychotic drugs in outpatients with schizophrenia in China. International Journal of Clinical Pharmacology and Therapeutics 46, 245-251. 